\title{
Online Educational Resources Regarding Cardiovascular Prevention
}

\author{
Aldo T. Marrocco \\ I. C. "G. Toniolo", Pisa, Italy \\ Email: aldo marrocco@yahoo.it \\ Received 22 February 2015; accepted 10 March 2015; published 19 March 2015 \\ Copyright (C) 2015 by author and Scientific Research Publishing Inc. \\ This work is licensed under the Creative Commons Attribution International License (CC BY). \\ http://creativecommons.org/licenses/by/4.0/

(c) (i) Open Access

\begin{abstract}
This paper presents several informative and educational tools aimed to explain some mechanisms of Miocardial Infarction and Stroke, their risk factors and their prevention. Such educational and informative documents are in English and consist of texts, images, videos, animations and games. They are downloadable for free and can be used with the method considered by the teacher as most appropriate. Among the aims of the study is to provide information on the effects which some of our daily actions may have on the circulatory system. The pathological processes affecting blood vessels may start to develop during childhood or adolescence as a consequence of physical inactivity, unhealthy diet, smoking and alcohol abuse. Notoriously, unhealthy behaviours learned in early age are very likely to be continued in the adulthood. By the time they can lead to important cardiovascular risk factors, such as high blood pressure, overweight or obesity, raised blood sugars and lipids. Some of the documents presented in this manuscript suggest that complying with cardivascular prevention measures may also, at the same time, reduce the risk of other diseases.
\end{abstract}

\section{Keywords}

Cardiovascular Prevention, Educational Resources, Animation, Teacher

\section{Introduction}

Blood and its circulation have important functions in the human body [1], and notoriously, the circulatory system may also have important disorders.

According to the "Atlas of Heart Disease and Stroke", cardiovascular (CV) diseases, in particular Myocardial Infarction (MI) and Stroke (S), cause every year the death of 17 million people on a global scale [2] [3]. Furthermore, still on a world scale, CV diseases are among the leading causes of disability [2].

In some high-income countries, over the recent decades, there has been a dramatic decline in the mortality for 
$\mathrm{CV}$ diseases due to improved control measures and prevention. In UK for instance, 58\% of such decline has been attributed to risk $(\mathrm{R})$ factors reduction.

The old stereotype of CV diseases affecting mainly middle-aged men in industrial countries does not apply any longer. Nowadays, even women and children are at R, and $80 \%$ of the global burden of CV diseases is concerning low- and middle-income countries [2].

A report of the World Health Organisation analyzes the situation in low-income countries as far as chronic diseases are concerned, and its trend [4].

Although most of such diseases are largely preventable, they continue to rise as a result of inadequacy of preventive measures, at least on a global scale.

Such situation has suggested the search of informative and educational resources on the internet, which can be used to awake the interest, and inform and motivate students in the study of the subject.

\section{Materials and Methods}

The informative and educational resources presented in this paper, downloaded for free from the internet, consist of text, images, videos, animations and games. They can be used for teaching about the prevention of cardiovascular diseases, with the method that the teacher feels most appropriate. All the teaching tools presented are in English, some animations are overlaid with explanations.

Some documents quoted in the last part of the manuscript suggest that complying with cardiovascular prevention measures can also contribute to prevent other diseases, such as cancer, for example.

\section{Discussion}

The lining of blood vessels, exposed to high concentrations of certain substances such as low-density lipoprotein cholesterol and free-radicals, undergoes several alterations leading to lesions, also known as plaques. This is one of the main underlying pathological processes leading to MI and S [3], it is known as atherosclerosis, as shown in an animation [5].

The formerly mentioned plaques may rupture, leading as a consequence to the formation of a thrombus large enough to block a coronary or a cerebral blood vessel.

When MI occurs, the blood supply to the heart is blocked and the damage due to lack of oxygen is permanent. When angina occurs, there is just a decrease of the blood flow to the heart [3].

Two animations deal with heart attack [6]. A document contains some questions and answers, 2 animations, and quizzes on the same subject [7].

Sometimes a coronary artery may temporarily contract causing the blood flow to decrease or stop; this may happen both in atherosclerotic and in normal-appearing vessels, and lead to a heart attack [7].

A thrombus may cause ischemic $\mathrm{S}$ in cerebral blood vessel. A hemorrhagic $\mathrm{S}$ results from bleeding after rupture of a blood vessel, whatever its cause: atherosclerosis, high blood pressure (BP) or aneurysm. Some animations may help to better understand the subject [5].

"Primary Prevention of Stroke" provides much information and can be used for an extended study of R factors, including the less known ones; its reference contains 572 titles where from several free full texts can be accessed [8].

Certain metabolic, physiological and behavioural R factors may cohexist in the same person, acting synergistically and increasing the R of developing acute events such as MI and S [3]. An animation is devoted to this subject [5].

A document provides R predictions charts [9]. They show the R of developing MI or S according to age, sex, $\mathrm{BP}$, smoking status, total blood cholesterol and presence or absence of diabetes, for several epidemiological subregions.

Since both MI and S are based on similar pathological process, the basis for their prevention is similar too.

Two Atlases provide information, with plenty of images and graphics about CV diseases, their $\mathrm{R}$ factors, prevention, education, legislation, economic costs, social determinants, population and systems approaches [2] [3].

The pathological processes, that affect medium and large-sized blood vessels, may start to develop during childhood and adolescence. This can be consequent to physical inactivity, unhealthy diet, smoking and alcohol abuse.

Notoriously, some behaviours learned in early age are very likely to be continued in the adulthood, and such 
unhealthy behaviours, by the time, lead to high BP, overweight or obesity, raised blood sugars and lipids [3] [10]. The poor and the less educated people are often the most exposed to higher levels of $\mathrm{R}$ behaviour [4].

\subsection{Blood Pressure}

Hypertension, often undiagnosed, is a $\mathrm{R}$ factor of paramount importance; an animation shows how to measure BP [11].

In order to allow our body to cope with stress or increased activity, our BP is continuously changing [12]; we can tolerate its temporary rise, but problems may occur when it is consistently high.

High BP may cause thickening of the muscles of the arteries thus resulting in narrower blood vessels, as shown in an interactive tool [12]. High BP increases the workload on the heart and the R of fat deposition in the arteries [5].

A page deals with the damages of high BP and with other R factors that may act synergically with it [11], from this document several animations can be opened [11].

The walls of our arteries are made of muscle and a semi-flexible tissue; when the hearth pumps blood, such tissues stretches like elastic to allow an easy flow. If the force pushing outwards on the arterial walls is often high, they may get stretched beyond their healthy limit. This may result in weak points that make the walls of the arteries more prone to ruptures. In addition, small tears in the arteries may be created that can catch debris like cholesterol and blood cells, thus increasing plaque build-up.

When BP is kept in the healthy range the $\mathrm{R}$ of these and other injuries is reduced [11]; from this page several animations can be viewed.

A healthy diet can provide an important contribution to BP management. Such diet should be high in fruits, vegetables, whole grain cereals, beans, omega 3 rich fish. Saturated and trans fats should be limited, as well as added sugars [11].

A high sodium intake is often associated with increased BP; such association is particularly strong in the elderly and in people that are hypertensive, diabetic, black, or have chronic kidney disease.

A document of the World Health Organisation, entitled "Sodium Intakes around the World", rich with tables and graphs, allows us to observe the great variability of sodium chloride intake in different countries [13].

A US website contains several PDFs that provide much information about sodium in our diet, and tips for its reduction [14]. As average in the US, $12 \%$ of the sodium intake is naturally contained in what people eat, $6 \%$ is added at the table and $5 \%$ during cooking at home, and $77 \%$ of the sodium intake is from processed and restaurant food.

Although the purchase of fresh products instead of processed ones is generally recommended to avoid salt excess, it must be mentioned that, for instance, much of the raw chicken and pork are injected with a sodium solution before sale.

Furthermore, it must be said that some foods, for instance some breads and cheeses, do not taste as salty as they effectively are.

The iodine content of the salt used in processed and restaurant food is little or nothing, thus having only a minimal influence on the iodine status of the population.

The preference for salty foods is not inborn, but rather acquired through exposition to them. Interestingly, the sense organ for taste can be re-trained over the time, so that the less sodium we ingest, the less we need.

A recent study found that the sodium content of school meals is twice as much as recommended. The content of one of the formerly mentioned PDFs is summarized by its title "Under Pressure: Strategies for Sodium Reduction in the School Environment".

A document provides information about foods lower and higher in sodium. It provides also a list of the main chemical forms of sodium added to the food, that for instance, can be present as glutamate or bicarbonate, and not only as chloride [15].

A situation that induces emotional or physical stress leads to an increase in hearth rate, muscle tension and BP. When the situation is normalized, then the body relaxes allowing all the formerly mentioned functions return to normal. Conversely, when situations that induce emotional or physical stress are, or are perceived as non stopping, then the body has no chance to relax thus leading to the negative "chronic stress". Such situation constitutes a R factor for hypertension, and may increase blood cholesterol level both directly and inducing to eat fatty foods. Furthermore, chronic stress may lead to other serious problems, including heart disease, and drug or alcohol 
abuse. An interactive health education tool explains some strategies aimed at preventing, managing and reducing stress [12].

A website provides tips aimed to prevent high BP; it deals also with ways to reduce stress [11].

A good network of social ties has helped many people to remain happy and healthy, despite a long list of life stresses [16].

A paper deals with the influence that the audience may have on BP of a speaker during a speech [17]. In this study, college students gave a speech in three different situations: alone, in presence of supportive audience or in the presence of non-supportive audience. Both systolic and diastolic BP exhibited a significantly smaller increase when the speech was given in the presence of a supportive audience, rather than in the presence of non-supportive audience ([17], Figure 1 and Figure 2).

Physical activity, practised gradually and without overdoing, provides several benefits including a lower resting BP. A sanitary check-up is recommended before starting exercise program, especially if medical conditions are present [11] [18].

It is also recommended to incorporate some yoga poses among the other exercises; a review deals with the CV benefits of such oriental practice [19].

Many scientific studies have unquestionably shown the benefit of physical activity in reducing the likelyhood of CV events. Nevertheless, a transient increase in CV R during exercise must be mentioned. Such transient increase in CV R is much lower among subjects that exercise regularly. Furthermore, contrary to common belief, most of hearth attacks occur in resting state rather than during physical activity [20]. Some symptoms that can indicate a problem are reported in the paper.

According to the American Health Association, to warm up before and cool down after the exercises, allows the heart to have a soft transition from rest to activity and back again. A longer warm up is recommended for people that have been inactive for long time and for the elderly.

During warm up, exercises and cool down it is important to practice breath control. Holding the breath should be avoided since it can raise BP [11]. According to the Harvard Medical School, deep abdominal breathing, involving the lowest portion of the lungs where many small blood vessels are located, may result in more stable $\mathrm{BP}$, slower heartbeat and relaxation [21].

A research that involved more than 19,000 subjects, including normotensives as well as hypertensives, has studied the BP changes occurring after a few deep breaths. The results show a lowered systolic BP for the group that practiced deep breathing as compared to controls [22]. The reduction was more significant for the people that had a higher BP. Conversely, an increase in BP was observed in subjects whose systolic BP was less than $100 \mathrm{~mm} \mathrm{Hg}$ ([22], Figure 2).

Contracting large muscle mass leads to the compression of great part of the vasculature, thus contributing to BP increase.

A paper deals with BP response in body builders during heavy weight lifting exercise [23]; the mean value of BP for the group has been 320/250, which has been reached during the double-leg press.

The graphs show the progressive growth of $\mathrm{BP}$ and heart rate during repetitions of weight lifting; the highest values for both are reached in the final part of such exercise ([23], Figure 2 and Figure 3). This is probably caused by fatigue, which may entail an increased involvement of accessory muscles.

A paper deals with the effects on BP of different breathing techniques during resistance exercises, as exhibited by twenty weight lifters [24]. The graphs of Figure 1 and Figure 2 summarize some results of the study, where breath holding during the exercises is linked to the greatest increase of BP, as compared to inhaling and exhaling during the same exercises.

\subsection{Blood Cholesterol}

Cholesterol (C) is a waxy fat-like substance, present and necessary all over the body. This latter is able to produce all the $\mathrm{C}$ that it needs.

An excess of $\mathrm{C}$ in the bloodstream, often undiagnosed, is a serious medical condition since it can be trapped in the artery walls, where it can build up thus creating the plaque; this results in narrower and less flexible vessels. An image helps to understand this concept [5]. The blood C concentration may rise from the age of 20 up to $60-65$.

A different chemical constitution causes blood and $\mathrm{C}$ not to mix, and the latter can travel in the former only if 
chemically bound to lipoproteins. Low density lipoproteins (LDL) transport C to the tissues, including the arteries, whereas high density lipoproteins (HDL) transport $\mathrm{C}$ to the liver, which then removes it from the body. Hence a high level of LDL $\mathrm{C}$ in the blood increases the R for arteries. Conversely, the HDL $\mathrm{C}$ has a protective effect and can slow, stop or even reverse the formation of plaque; it can also decrease the $\mathrm{C}$ content of unstable plaques thus decreasing their likelihood to burst and cause a heart attack. An image deals with this subject [5].

In pre-menopausal women, HDL C levels are kept high by hormonal control; this may help explain why, during such part of life, they are relatively more protected than men from coronary heart disease [2].

The velocity of LDL C production and of its removal is only partly inherited; people with no family history of high $\mathrm{C}$ may develop such condition. Everybody can select a lifestyle that contributes to prevent its buildup.

Nutrients that more than others rise our LDL $\mathrm{C}$ are the saturated fats and the $\mathrm{C}$ present in animal products. Saturated fats are also contained in some vegetable oils such as coconut and palm oils. Trans fats produce an even higher $\mathrm{R}$ for the heart than the saturated ones, since in addition to increasing LDL $\mathrm{C}$, they lower HDL C. They are found mainly in hydrogenated vegetable oils such as hard margarines and shortenings. According to a document of the Harvard School of Public Health, an extra 2\% of trans fats in the diet results in a $23 \%$ increase of coronary heart disease [25].

Conversely, unsaturated fats can be considered beneficial, provided that their intake is not excessive so as to avoid overweight.

In Mauritius, palm oil formerly commonly used for cooking, has been substituted with soy oil; this change has lowered $\mathrm{C}$ levels but has not affected obesity [2].

Swapping dietary saturated fats with refined carbohydrates, such as the ones contained in white bread and white rice, or in sugary drinks, lowers both LDL C and HDL C increasing at the same time triglycerids [25]. This entails a negative net effect for the hearth. The CV R can be reduced substituting the calories obtained from saturated fats with the ones of unsaturated fats, whole grains, nuts, beans, fruit and vegetables [25].

Plants may contain insoluble and soluble fibers; the former helps colon to work properly whereas the latter blocks the absorption of $\mathrm{C}$ and fats from the intestine into the bloodstream, thanks to its gel-like consistency.

A booklet of US Department of Health and Human Services provides tips for LDL C reduction. Box 7 shows the amounts that, on the base of research, are expected to be lost through dietary and weight changes [26]. For instance, adding 5 - 10 grams of soluble fiber a day to the food may reduce LDL C by $3 \%-5 \%$. Overweight people that lose 10 pounds may reduce by $5 \%-8 \%$ their LDL C.

Admittedly, dietary fiber may limit calcium absorption [27].

An interactive health education tool deals with C [12].

Excess weight and physical inactivity lead to an increase in LDL C and another type of noxious fats called triglycerides, lowering at the same time the beneficial HDL C. Smoking also contributes to increase triglycerids and to decrease HDL C.

\subsection{Blood Sugar}

Type 2 diabetes, often undetected, occurs when our cells have not enough receptors that allow glucose to enter, thus resulting in accumulation of sugar at high concentrations in the blood.

The exposition of large and small blood vessels to high blood sugar concentrations increases the likelihood to develop high blood $\mathrm{C}$ concentration [28] and may lead to arteriosclerosis. Two interactive health education tools help to develop a better understanding of diabetes and deal with how to prevent and cope with such important CV R factor [12].

Type 2 diabetes is a serious medical condition formerly concerning mainly adults over age 45 ; now is becoming more and more common among young people as a consequence of the diffusion of obesity [29].

Two interactive animations allow us to observe the increased prevalence of diabetes and the parallel rise of obesity in the US ([30], Box 1 and Box 2).

Some interactive quizzes deal with the increase in size of food portions in US restaurants, from 20 years ago up to now, when a parallel increase in the body weight of the population has been observed [12]. Through this website it can be learned how much physical activity would be required to burn the extra calories which nowadays the portions provide.

"Do Increased Portion Sizes Affect How Much We Eat?" deals with the consequences which increased portion sizes in US supermarkets and vending machines, may have on the eating patterns of the population [31]. 
A comic book deals with diabetes; the same website contains also crosswords about healthy habits [32].

Positive emotions may act on the neuroendocrine system suppressing blood sugar elevation. Conversely, negative emotions such as fear and anxiety are known to raise blood sugar level. The results of a study entitled "Laughter Lowered the Increase in Postprandial Blood Glucose" are summarized by its title [33].

Exercise helps e.g. to cope with stress and to feel relaxed, strengthen the hearth, and control several $\mathrm{R}$ factors including overweight and type 2 diabetes, as shown in an interactive health education tool [12].

Many studies agree about the role of dietary carbohydrates in the development of type 2 diabetes. Women that often ate whole grains were less exposed to type 2 diabetes than the ones that rarely ate them. According to the Harvard School of Public Health, the bran and the fiber which whole grains contain slow the digestive enzymatic process that leads to the breakdown of starches into glucose [34]. A slower release of sugar in the bloodstream results in a lesser insulin secretion with consequent reduced stress for the organism, thus constituting a protective factor against type 2 diabetes [35].

The glycemic index of foods deals with the velocity of release of the sugar which they contain in the bloodstream.

A food with high glycemic index leads to a high peak in postprandial blood glucose concentration. A food that contains as many carbohydrates as the former, but has lower glycemic index, leads to lower postprandial peak [36].

\subsection{Overweight and Obesity}

In the Atlas of Hearth Diseases and Stroke, a page is specifically devoted to obesity, as a R factor [2].

All the studies agree that excess abdominal fat contributes more importantly to CV diseases than excess subcutaneous fat. A document of the Harvard Medical School provides simple instructions to determine abdominal obesity [37].

Notoriously, childhood obesity is getting common in several countries; a governmental website, which has many interesting links, analyzes its causes in the US [38]. A page from the same website deals with how to measure childhood obesity and related health Rs, both present and future [38].

Diets rich with lower glycemic index foods may lead to higher blood HDL C and contribute to protect from CV diseases and obesity [35] [36].

A document provides the international table of glycemic index [36]. This table allows us to observe that differences exist among apparently similar foods. They depend on several factors, e.g. type of flour used in its preparation, or botanical differences such as in the case of rice from different countries. Furthermore, cooking time may lead to different starch gelatinization degree, which may influence the glycemic index.

The acidity of the meal influences gastric emptying velocity, consequently affecting postprandial blood sugar concentration.

A study has investigated the voluntary food intake in obese pubertal boys, after having ingested meals that differ only in glycemic index [39]. The ingestion of a high-glycemic index meal leads to a high blood glucose concentration soon after the meal, which then decreases quickly within a few hours. This is shown in a graph that compares postprandial blood glucose detected after the ingestion of high- and medium-glycemic index meals, which provide equal amounts of carbohydrates, proteins and fats ([39], first graph of Figure 1).

The medium-glycemic index meal leads to lower blood glucose concentrations soon after the meal, and a slower decrease in the following hours, thus resulting in a delayed return of hunger in the boys considered in this study ([39], Figure 2). The ad libitum food intake after the meals was determined, and in the case of highglicemic index it resulted 53\% higher than in others ([39], Figure 3).

Another document deals with the same subject [40].

According to the World Health Organization, supportive environments and communities may help people to be more physically active [41]. An animation deals with effects of physical activity on heart, metabolism, blood vessels and $\mathrm{BP}[5]$.

In $1969,48 \%$ of US children usually walked or bicycled to school, whereas in 2009 such percent dropped to $13 \%$. The reasons of such reduction, according to a nationwide survey of parents, include increased traffic-related dangers, as reported in a document [42].

A guide is designed to support the development of safe routes to school [42]. It may encourage and enable children to bicycle or walk to school safely, thus favoring physical activity and simultaneously contributing to 
reduce air pollution [42]. The website is very wide and covers several aspects of the matter including, among other things, education and engineering [42].

Groups of children, organized for walking to school accompanied by one or more adults, constitute a so called "Walking School Bus" [42]. A document provides information about it, and some links, for instance that of "International Walk to School" [42].

The Wisconsin Department of Health Services-Nutrition Physical Activity and Obesity Program-to encourage healthy eating and physical activity has produced a garden toolkit [43]. Involving children in school garden activity may develop their nutrition knowledge and their preference for vegetables. In addition gardening is a way to increase physical activity, which for instance allows adults to burn about 300 calories per hour.

Two documents provide information about safety in school gardens, including lead contamination and other possible hazards in soils [44] [45].

The cardiovascular risk from tobacco, alcohol and drugs abuse, pollution and infectious diseases

Smoking, among many other damages, may lead to deposition of cholesterol in blood vessels and could also cause blood to clot. This results in narrower blood vessels as shown in an interactive tool [12].

The damage of smoking to human health is shown in two animations [5] [46], and explained in "Highlight Sheets" [47].

A booklet by the U.S. Surgeon General, among other things, deals with social, physical and environmental influences that may lead young people to smoke, and contains some suggestions for the parents [48].

A website provides information about the adverse consequences of smoke and contains two links: "second hand smoke" and "smoking during pregnancy" [49].

"Guide to Quitting Smoking" produced by the American Cancer Society, and a poster deal with the benefits over time after quitting [49] [50].

"Smoking-Tips on How to Quit" is the title of a shorter guide on the same subject [51]; the animation "Smoking Cessation" [5] is also available.

A paper deals with the relations between alcohol and CV system [52].

A moderate alcohol consumption may have the beneficial effects of increasing the concentration of HDL C and inhibit blood clot formation or promote its dissolution; it may also lower the noxious plasmatic triglycerides. Light to moderate alcohol consumption reduces ischemic stroke $\mathrm{R}$ caused by plaque buildup.

According to a study where 1 is assumed as relative $\mathrm{R}$ of $\mathrm{S}$ for the abstainers, the $\mathrm{R}$ associated with the consumption of 1 to 2 drinks per day is 0.72 , but rises to 1.69 for those who consumed more than 5 drinks per day [8]. The protective effect of moderate alcohol use is considered important only for middle aged and old people, since their CV R is higher. In young people the adverse effects of alcohol consumption outweigh the benefits [4].

Alcohol abuse is linked with $\mathrm{CV}$ consequences, i.e. hypertension, cardiomyopathy, cardiac arrhythmia and stroke.

Heavy drinking is associated with increased activity of the sympathetic nervous system that has also an important role in constricting blood vessels whose consequence is a higher BP. Furthermore the sensibility of the baroreceptors located in the walls of the arteries is decreased; consequently the central nervous system does not receive the necessary information for a correct BP control.

Alcohol can have negative effects on cardiac muscles, which lead to enlarged hearth and reduce its output as shown in an animation [5].

In a research, heavy drinkers showed a two-fold increased $\mathrm{R}$ of arrhythmia, as compared to people that consumed less than one alcoholic drink per day; an animation shows the phenomenon [5]. Atrial fibrillation is a type of arrhythmia that may create conditions for blood clots formation in the atria and their propagation, thus increasing stroke $\mathrm{R}$ or damaging other organs [53].

A document deals with CV and other health consequences of drugs abuse [54].

According to a study, drug abuse increased stroke $\mathrm{R}$ by 6.5 times considering all age groups, but the increase was by 11.2 times, when only people $<35$ years old were considered [8]. This may suggest how much more exposed young people are (author's note).

According to a document of the National Institute of Environmental Health Sciences, some of the chemicals entered in the body, instead of being transformed by the liver into harmless substances, are converted into free radicals. The proteins in the blood may react with such free radicals forming fatty deposits that constitute the formerly mentioned plaques [55]. 
Some infectious diseases may have CV consequences, such as the rheumatic fever [2]. Such disease often follows an untreated beta-haemolitic streptococcal troath infection in children. Such disease, that may lead to a permanent damage at the valves of the heart, has a disproportionate impact on young people living in low income countries [3].

Complying with CV prevention measures may contribute to prevent other diseases. A few exemplifying papers about this regard are quoted in this last part of the manuscript.

A document of the World Health Organisation and a review entitled "Diet, Nutrition and the Prevention of Cancer" suggest the numerous similarities between CV and the prevention of cancer in several sites of the body [56] [57].

An animation deals with the numerous negative effects of obesity on health [46].

According to a document of the International Agency for Research on Cancer (IARC), 90\% of lung tumor cases are attributed to cigarette smoking [58]. The document provides information about the $\mathrm{R}$ of cancer in several sites of the body induced by the smoke and describes, among other things, the related benefits of quitting.

A paper entitled "Developmental Consequences of Prenatal Tobacco Exposure" is quoted. In most studies, according to such review, prenatal tobacco exposure is linked to adverse neurodevelopmental aftermaths [59].

"Cigarette Smoking and Infection" describes some mechanical and structural changes in the respiratory tract, that may occur as consequence of smoking, and that are thought to predispose it to infections [60].

Cigarette smoking is associated with several alterations in the immune system function such as for instance, depression of antibody responses and reduced phagocytic activity, which can expose human body to several infections. Several immunologic abnormalities appeared to be reversible after quitting smoking.

Second hand tobacco smoke exposure in children is also associated with increased $\mathrm{R}$ of meningococcal disease [60].

Excessive prenatal alcohol exposure is also linked to congenital CV malformations [52] [61].

A IARC document deals with cancer $\mathrm{R}$ in some sites of the body linked to alcohol drinking [62].

How alcohol affects cancer R is not completely understood. However, for example, alcohol is supposed to behave as an irritant; when damaged cells try to repair themselves, DNA changes may occur that can be a step toward cancer [63].

A document deals with consequences of underage drinking [48].

According to the American Cancer Society, alcohol use combined with smoking may greatly increase the R of cancer for mouth, pharynx, larynx and esophagus [64]. Alcohol is supposed to act as a solvent that allows dangerous chemicals of tobacco to get into the cells lining the digestive tract.

"A study of the interaction of alcohol drinking and tobacco smoking among French cases of laryngeal cancer" is the title of a paper that clearly summarizes its content. The study has found a strong synergic action of alcohol and tobacco together, that multiplicated the R by 289.4 for subjects that were simultaneously heavy drinkers and smokers, compared to light drinkers and smokers [63].

Physical activities, load bearing in particular, and especially if practiced in young age, contribute to increase bone mineral density thus strengthening the skeleton and reducing fracture $\mathrm{R}$.

Such benefits can be maintained later in life in physically active people, or may be partially lost as consequence of sedentary lifestyle [65].

An interactive animation of the University of Washington provides information about bone density, in different parts of the body, in athletes from several disciplines and compared to non athletes [66].

According to the National Cancer Institute, regular physical activity constitutes a protective factor against colon, breast, endometrium, lung and prostate tumors [67].

A document deals with a lowered $\mathrm{R}$ for incident cataract, associated with strenuous physical activity and low body mass index [68].

A review of scientific studies suggests that limiting salt consumption is a good strategy for reducing stomach cancer R [69].

Furthermore, according to a study that involved male and female subjects aged $20-79$, an excess of sodium in the diet is linked with a slightly increased urinary calcium excretion. This should be considered for the prevention of osteoporosis in populations whose calcium intake is generally low [70].

A review provides a critical analysis of the scientific evidences on the role that glycemic index of the food may have in the prevention of some chronic diseases [35].

Chronic stress is associated to health problems other than CV diseases; for instance, low white blood cell 
counts and altered immune function have been reported to be linked with it. Pains caused by arthritis, susceptibility to infections, asthma and headaches are likely to be intensified as a consequence of stress [16]. Stress is often associated to overeating and weight gain.

The website provides explanations about situations that produce stress and tips for coping with it [16].

A website produced by the American Association for Clinical Chemistry provides explanations on the lab results of blood tests, that could contribute to complete the teaching unit [71]. For example, it helps to understand the meaning of reference ranges [71]. Information can also be accessed through the list of tests, the list of conditions/diseases, and the list of screening recommendations.

\section{Acknowledgements}

The author would like to thank Dr. Liu Lin for information kindly provided.

\section{References}

[1] Virtual Medical Centre (2012) Blood Function and Composition. http://www.virtualmedicalcentre.com/anatomy/blood-function-and-composition/30

[2] World Health Organisation (2012) The Atlas of Heart Disease and Stroke. http://www.who.int/mediacentre/news/releases/2004/pr68/en/index.html

[3] World Health Organisation (2011) Global Atlas on Cardiovascular Disease Prevention and Control. http://whqlibdoc.who.int/publications/2011/9789241564373 eng.pdf

[4] World Health Organisation (2005) Preventing Chronic Diseases: A Vital Investment. http://www.who.int/chp/chronic disease_report/full_report.pdf

[5] Medmovie.com. (2007) Cardiovascular Glossary Media Library. http://www.medmovie.com/mmdatabase/MediaPlayer.aspx?ClientID $=65$

[6] Medindia. Health Animations A - Z. http://www.medindia.net/animation/index.htm\#k

[7] American Heart Association (2013) About Heart Attacks. http://www.heart.org/HEARTORG/Conditions/HeartAttack/AboutHeartAttacks/About-Heart-Attacks_UCM_002038 Article.jsp

[8] American Heart Association (2006) Primary Prevention of Ischemic Stroke. http://stroke.ahajournals.org/content/37/6/1583.full

[9] World Health Organisation/ISH Risk Prediction Charts. http://new.paho.org/hq/dmdocuments/2010/colour charts 24 Aug_07.pdf

[10] Celermajer, D.S. and Ayer, J.G.J. (2006) Childhood Risk Factors for Adult Cardiovascular Disease and Primary Prevention in Childhood. Heart, 92, 1701-1706. http://www.ncbi.nlm.nih.gov/pmc/articles/PMC1861256/ http://dx.doi.org/10.1136/hrt.2005.081760

[11] American Heart Association (2012) About HBP; Why HBP Matters; Your Risk for HBP; Symptoms, Diagnosis \& Monitoring of HBP; Prevention \& Treatment of HBP.

http://www.heart.org/HEARTORG/Conditions/HighBloodPressure/High-Blood-Pressure-or-Hypertension_UCM_0020 20 SubHomePage.jsp

[12] US Department of Health and Human Services (2012) Interactive Health Education Tools from the National Institutes of Health (NIH). http://diabetes.niddk.nih.gov/resources/HealthTools/index.aspx

[13] Elliott, P. and Brown, I. (2006) Sodium Intakes around the World. http://www.who.int/dietphysicalactivity/Elliot-brown-2007.pdf

[14] Centers for Diseases Control and Prevention (2012) Division for Heart Diseases and Stroke Prevention. http://www.cdc.gov/dhdsp/

[15] National Kidney Disease Education Program (2011) Sodium. http://nkdep.nih.gov/resources/nutrition-sodium-508.pdf

[16] University of Maryland Medical Centre (2011) Stress. http://www.umm.edu/patiented/articles/stress_000031.htm

[17] Stephen, G.L., Mata, K.A. and Evans, G.V. (1993) Social Support Lowers Cardiovascular Reactivity to an Acute Stressor. Psychosomatic Medicine. http://astro.temple.edu/ slepore/Lepore PM 1993

[18] University of Iowa Hospitals \& Clinics (2008) Health Information Topics for Exercise and Fitness. http://www.uihealthcare.org/Adam/?/HIE\%20Multimedia/1/001941

[19] Kyeongra, Y. (2007) A Review of Yoga Program for Four Risk Factors of Chronic Diseases. Evidence-Based Complementary and Alternative Medicine, 4, 487-491. 
http://www.ncbi.nlm.nih.gov/pmc/articles/PMC2176145/?tool=pubmed

[20] American Heart Association (2003) Exercise and Cardiovascular Health. http://circ.ahajournals.org/content/107/1/e2.full

[21] Harvard Medical School (2009) Take a Deep Breath. http://www.health.harvard.edu/newsletters/Harvard_Mental_Health_Letter/2009/May/Take-a-deep-breath

[22] Mori, H., Yamamoto, H., Kuwashima, M., Saito, S., Ukai, H., Hirao, K., et al. (2005) How Does Deep Breathing Affect Office Blood Pressure and Pulse Rate? Nature.com, 499-504. http://www.nature.com/hr/journal/v28/n6/pdf/hr200562a.pdf

[23] Mac Dougall, J.D., Tuxen, T., Sale, D.G., Moroz, J.R. and Sutton, J.R. (1984) Arterial Blood Pressure Response to Heavy Resistance Exercise. Luzimar Texeira, 785-790. http://www.luzimarteixeira.com.br/wp-content/uploads/2010/08/pressao-arterial-e-exercicio-resistido.pdf

[24] Lisenbardt, S.T., Thomas, T.R. and Madsen, R.W. (1992) Effect of Breathing Techniques on Blood Pressure Response to Resistance Exercise. British Journal of Sports Medicine, 26, 97-100. http://bjsm.bmj.com/content/26/2/97.full.pdf

[25] Harvard School of Public Health (2013) The Nutrition Source. http://www.hsph.harvard.edu/nutritionsource/what-should-you-eat/fats-full-story/index.html\#references

[26] US Department of Health and Human Services (2005) Your Guide to Lowering Cholesterol with TLC. http://www.nhlbi.nih.gov/health/public/heart/chol/chol_tlc.pdf

[27] Massachussets Institute of Technology (2007) http://web.mit.edu/athletics/sportsmedicine/wcrminerals.html.

[28] Centers for Diseases Control and Prevention (2010) Cholesterol-Risk Factors. http://www.cdc.gov/cholesterol/risk_factors.htm

[29] US Department of Health and Human Services (2012) Diabetes. http://diabetes.niddk.nih.gov/

[30] Laura, D. and Mc Entyre, J. (2004) National Center for Biotechnology Information (US). The Genetic Landscape of Diabetes. http://www.ncbi.nlm.nih.gov/books/NBK1671/

[31] Centers for Diseases Control and Prevention (2006) Do Increased Portion Sizes Affect How Much We Eat? http://www.cdc.gov/nccdphp/dnpa/nutrition/pdf/portion_size_research.pdf

[32] University of Wisconsin-Madison (2015) HipHop2Health Comic Book. http://apps2.pharmacy.wisc.edu/unity/target.cfm

[33] Keiko, H., Hayashi, T., Iwanaga, S., Kawai, K., Ishii, H., Shoji, S. and Murakami, K. (2003) Laughter Lowered the Increase in Postprandial Blood Glucose. Diabetes Care, 26, 1651-1652. http://care.diabetesjournals.org/content/26/5/1651.long

[34] Harvard School of Public Health (2012) Simple Steps to Preventing Diabetes. http://www.hsph.harvard.edu/nutritionsource/diabetes-prevention/preventing-diabetes-full-story/index.html\#references

[35] Augustin, L.S., Franceschi, S., Jenkins, D.J.A., et al. (2002) Glycemic Index in Chronic Disease: A Review. European Journal of Clinical Nutrition, 56, 1049-1071. http://www.nature.com/ejcn/journal/v56/n11/full/1601454a.html

[36] Foster-Powell, K., Holt, S. and Brand-Miller, J.C. (2002) International Table of Glycemic Index and Glycemic Load Values: 2002. The American Journal of Clinical Nutrition, 76, 5-56. http://ajcn.nutrition.org/content/76/1/5.full

[37] The Harvard Medical School (2009) Abdominal Obesity and Your Health. http://www.health.harvard.edu/fhg/updates/abdominal-obesity-and-your-health.shtml

[38] Centers for Diseases Control and Prevention (2012) Overweight and Obesity. http://www.cdc.gov/obesity/childhood/index.html

[39] Ludwig, D.S., Majzoub, J.A., Al-Zahrani, A., Dallal, G.E., Blanco, I. and Roberts, S.B. (1999) High Glicaemic Index Foods, Overeating and Obesity. Pediatrics, 103, e26. http://pediatrics.aappublications.org/content/103/3/e26.full http://dx.doi.org/10.1542/peds.103.3.e26

[40] Warren, J.M., Jeya, C.K. and Simonite, V. (2003) Low Glycemic Index Breakfasts and Reduced Food Intake in Preadolescent Children. Pediatrics, 112, e414. http://pediatrics.aappublications.org/content/112/5/e414.full.pdf

[41] World Health Organization (2012) Childhood Overweight and Obesity. http://www.who.int/dietphysicalactivity/childhood/en/

[42] Saferoutesinfo.org. (2012) Safe Routes to School Online Guide. http://guide.saferoutesinfo.org/

[43] Wisconsin Department of Health Services (2012) Nutrition, Physical Activity and Obesity Prevention Program. http://www.dhs.wisconsin.gov/health/physicalactivity/

[44] University of Maryland (2010) Food Safety in the School Garden. http://extension.umd.edu/growit/youth-gardening/food-safety-school-garden 
[45] US Department of Agriculture, NRCS (2011) Soil Education. http://soils.usda.gov/education/

[46] myDr for a Healthy Australia. Animation: Effects of Obesity. http://www.mydr.com.au/index/A

[47] Centers for Disease Control and Prevention (2012) Smoking and Tobacco Use. http://www.cdc.gov/tobacco/data_statistics/sgr/2010/index.htm

[48] A Report of the Surgeon General (2012) Preventing Alcohol Use among Youth and Young Adults. http://www.cdc.gov/tobacco/data statistics/sgr/2012/consumer booklet/pdfs/consumer.pdf

[49] Centers for Diseases Control and Prevention (2012) Smoking and Tobacco Use. http://www.cdc.gov/tobacco/

[50] American Cancer Society (2012) Guide to Quitting Smoking. http://www.cancer.org/healthy/stayawayfromtobacco/guidetoquittingsmoking/index

[51] Medline Plus, National Institutes of Health (2012) Smoking - Tips on How to Quit. http://www.nlm.nih.gov/medlineplus/ency/article/001992.htm

[52] Zakhari, S. (1997) Alcohol and the Cardiovascular System: Molecular Mechanisms for Beneficial and Harmful Action. Vol. 21, 21-29. http://pubs.niaaa.nih.gov/publications/arh21-1/21.pdf

[53] American Heart Association (2012) Why Arrhythmia Matters. http://www.heart.org/HEARTORG/Conditions/Arrhythmia/WhyArrhythmiaMatters/Why-Arrhythmia-Matters UCM 002023 Article.jsp

[54] National Institute on Drug Abuse (2012) Medical Consequences on Drug Abuse. http://www.drugabuse.gov/related-topics/medical-consequences-drug-abuse

[55] The National Institute of Environmental Health Sciences (2012) Lesson Resources for Teachers. http://www.niehs.nih.gov/health/scied/teachers/

[56] World Health Organization (2012) Cancer Prevention. http://www.who.int/cancer/prevention/en/

[57] Timothy, J.K., Schatzkin, A., Willett, W.C., et al. (2004) Diet, Nutrition and the Prevention of Cancer. Public Health Nutrition, 7, 187-200. http://dx.doi.org/10.1079/PHN2003588 http://cdrwww.who.int/nutrition/publications/public health nut6.pdf

[58] International Agency for Research on Cancer (2002) Tobacco Smoke and Involuntary Smoking. http://monographs.iarc.fr/ENG/Monographs/vol83/volume83.pdf

[59] Cornelius, M.D. and Day, N. (2009) Developmental Consequences of Prenatal Tobacco Exposure. Current Opinion in Neurology, 22, 121-125. http://www.ncbi.nlm.nih.gov/pmc/articles/PMC2745235/ http://dx.doi.org/10.1097/WCO.0b013e328326f6dc

[60] Arcavi, L. and Benowitz, N.L. (2004) Cigarette Smoking and Infection. Archives of Internal Medicine, 164, 2206-2216. http://archinte.jamanetwork.com/article. aspx?articleid=217624\#qundefined http://dx.doi.org/10.1001/archinte.164.20.2206

[61] American Academy of Pediatrics - Committee on Substance Abuse and Committee on Children with Disabilities (2000) Fetal Alcohol Syndrome and Alcohol-Related Neurodevelopmental Disorders. http://pediatrics.aappublications.org/content/106/2/358.long

[62] International Agency for Research on Cancer (1998) Alcohol Drinking. http://monographs.iarc.fr/ENG/Monographs/vol44/volume44.pdf

[63] Guenel, P., Chastang, J.F., Luce, D., Leclerc, A. and Brugire, J. (1988) A Study of the Interaction of Alcohol Drinking and Tobacco Smoking among French Cases of Laryngeal Cancer. Journal of Epidemiology and Community Health, $\mathbf{4 2}$, 350-354. http://jech.bmj.com/content/42/4/350.full.pdf + html http://dx.doi.org/10.1136/jech.42.4.350

[64] American Cancer Society (2012) Alcohol Use and Cancer. http://www.cancer.org/cancer/cancercauses/dietandphysicalactivity/alcohol-use-and-cancer

[65] Karlsson, M.K. (2004) Physical Activity, Skeletal Health and Fractures in a Long Term Perspective. Journal of Musculoskeletal and Neuronal Interactions, 4, 12-21. http://www.ismni.org/jmni/pdf/15/03KARLSSON.pdf

[66] University of Washington (2004) Bone Biology for Kids. http://depts.washington.edu/bonebio/index.html

[67] National Cancer Institute (2009) Physical Activity and Cancer. http://www.cancer.gov/cancertopics/factsheet/prevention/physicalactivity

[68] Williams, P.T. (2008) Prospective Epidemiological Cohort Study of Reduced Risk for Incident Cataract with Vigorous Physical Activity and Cardiorespiratory Fitness during a 7-Year Follow-Up. Investigative Ophthalmology Visual Science, 50, $95-100$. http://www.iovs.org/content/50/1/95.long http://dx.doi.org/10.1167/iovs.08-1797

[69] Xiao-Qin, W., Terry, P.D. and Hong, Y. (2009) Review of Salt Consumption and Cancer Risk: Epidemiological and 
Biological Evidence. World Journal of Gastroenterology, 15, 2204-2213.

http://www.ncbi.nlm.nih.gov/pmc/articles/PMC2682234/

[70] Roichi, I. and Yasuo, S. (1996) Sodium Excretion in Relation to Calcium and Hydroxyproline Excretion in a Healthy Japanese Population. The American Journal of Clinical Nutrition, 63, 735-740. http://ajcn.nutrition.org/content/63/5/735.full.pdf + html

[71] American Association for Clinical Chemistry (2012) Lab Tests Online. http://www.labtestsonline.org/understanding/index.html 